\title{
Simulation of Formation Damage after Long-Term Water Flooding
}

\author{
Liu He, ${ }^{1}$ Gao Yang, ${ }^{1}$ Li Guoxin, ${ }^{2}$ and Li Yiliang ${ }^{1}$ \\ ${ }^{1}$ RIPED, PetroChina, Beijing 100083, China \\ ${ }^{2}$ Exploration \& Production Company, PetroChina, Beijing 100083, China \\ Correspondence should be addressed to Liu He; liuhe@petrochina.com.cn
}

Received 30 January 2013; Revised 18 April 2013; Accepted 18 April 2013

Academic Editor: Alireza Bahadori

Copyright (c) 2013 Liu He et al. This is an open access article distributed under the Creative Commons Attribution License, which permits unrestricted use, distribution, and reproduction in any medium, provided the original work is properly cited.

\begin{abstract}
Water flooding is a commonly used technology for enhancing oil recovery. Its main mechanism is to maintain higher pressure to sweep oil towards production wells. However, the strong water flooding will cause higher compression pressure around the injection wellbore. This high pressure in the reservoir causes stress redistribution and higher stress near the wellbore which induces material damage and permeability change. We developed a fluid-solid coupling finite element model to simulate and quantitatively analyze the pressure evolution in the reservoir as well as damage and permeability change in the formation during long-term water flooding process. The obtained results offer theoretical understanding of the benefits (pore pressure increase in the simulation domain), rock damage, permeability change of long-term water flooding, and the insights of how to detect and prevent wellbore failure and collapse due to water flooding.
\end{abstract}

\section{Introduction}

Water flooding is a worldwide used technology for enhancing oil recovery. Its main mechanism is to maintain higher pressure to sweep oil towards production wells. The efficiency and key considerations about the technology have been studied $[1,2]$. However the injected water will cause the pressure around the injection wellbore to be much higher than that farther away from the well [3]. This high pressure in the reservoir causes stress redistribution and higher stress near the wellbore which induces material damage and permeability change. Experimental results show that dramatic increase of permeability occurs after rock damage [4-6]. Different mechanical models of describing the rock damage and permeability change have been established. Rutqvist et al. [7] proposed that the permeability is an exponential function of the equivalent strain based on the field measurement data of tunnel excavation problem. According to the uniaxial compression tests of rock material, Tang et al. [5] found that permeability jumps up steeply accompanying rock damage. Other damage models can be consulted in the literature such as Loland damage model, Mazars damage model, and Sidoroff damage model [8].

In the present paper, an axial symmetrical fluid-solid coupling finite element model is established to simulate the water flooding process. The pressure evolution in the reservoir as well as damage and permeability change in the formation during long-term water flooding procedure is studied. The numerical results demonstrate that after 5year water flooding, the maximum pore pressure is increased remarkably. The formation damages gradually near the water injection wellbore and in the damaged area, the reservoir permeability jumps up. The area of damage is enlarged during the water flooding process. The efficiency of water injection is significant. Rock damage and permeability change near the wellbore should be considered when planning a water injection well due to the potential risks.

Fully coupled fluid-solid finite element simulation of water-injection is rarely seen in the literature to our knowledge. The present model can be used to predict the formation pressure evolution and the formation property variation caused by water injection. It is valuable for engineering design. 


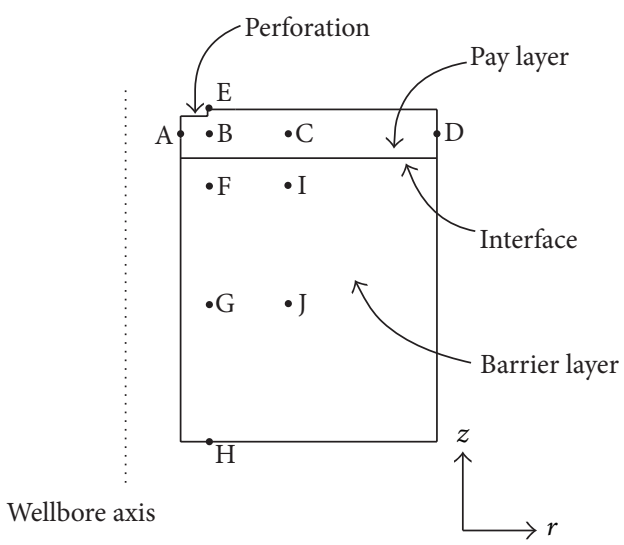

FIGURE 1: The computational model (a meridian plane).

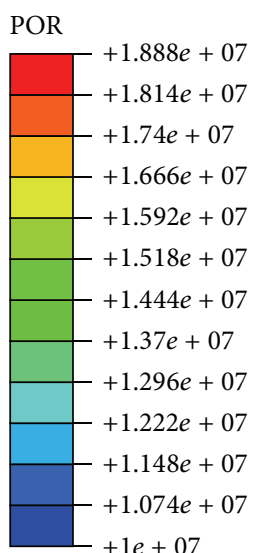

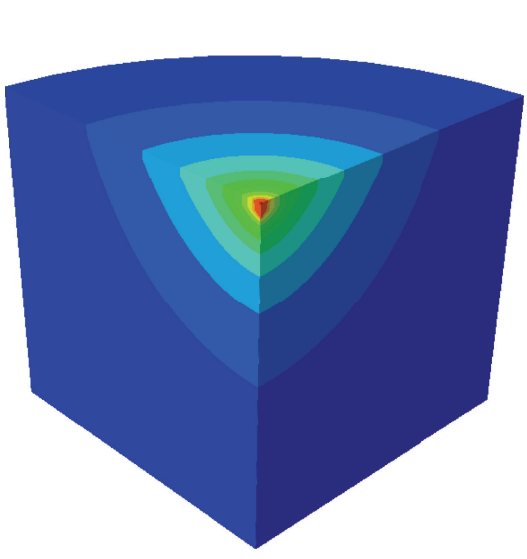

(a) One year

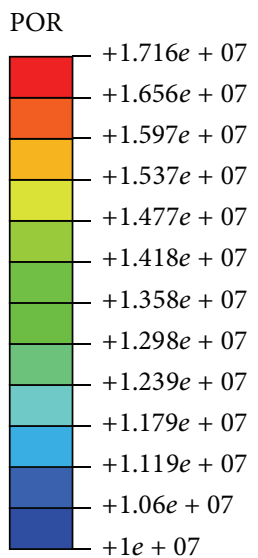

$+1 e+07$

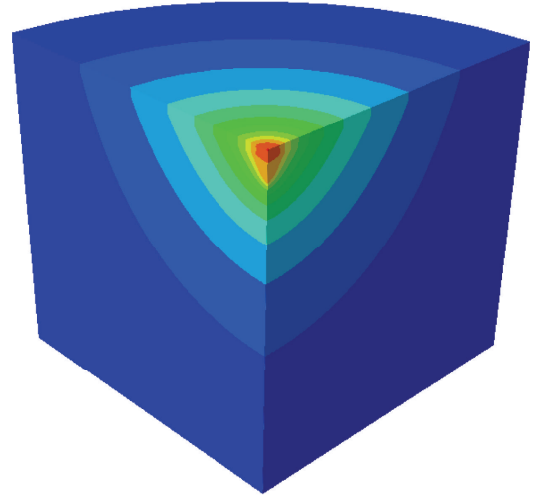

(b) Two years
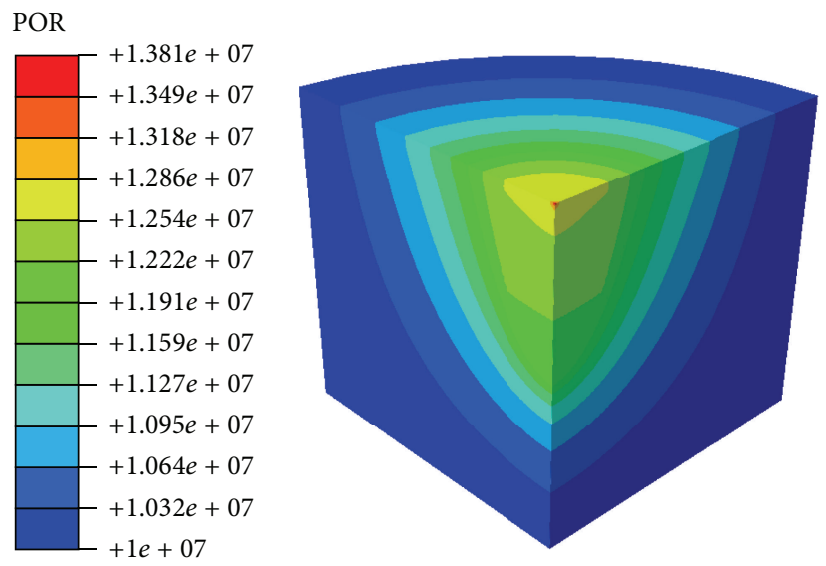

(c) Five years

FIgURE 2: Pore pressure distributions at different injection years (The model is rotated by $90^{\circ}$ ).

\section{Mathematical Model}

(1) Governing Equations of Stress-Seepage Flow Coupling Field in Formation. In the current configuration, the equilibrium equation of porous formation can be written as [9] where $\boldsymbol{\sigma}$ is the total stress matrix in the formation and $\mathbf{f}$ is the body force vector.

The effective stress couples solid deformation with fluid flow by the following formulation [10]:

$$
\nabla \cdot \boldsymbol{\sigma}+\mathbf{f}=\mathbf{0}
$$

$$
\overline{\boldsymbol{\sigma}}=\boldsymbol{\sigma}-p_{w} \mathbf{I},
$$




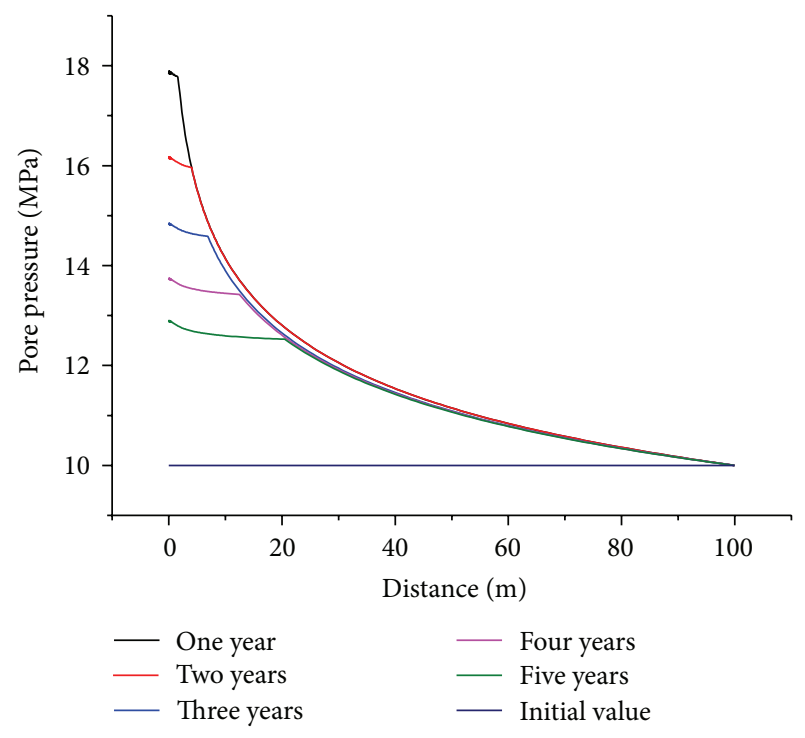

FIgURE 3: Pore pressure evolution along AD line.

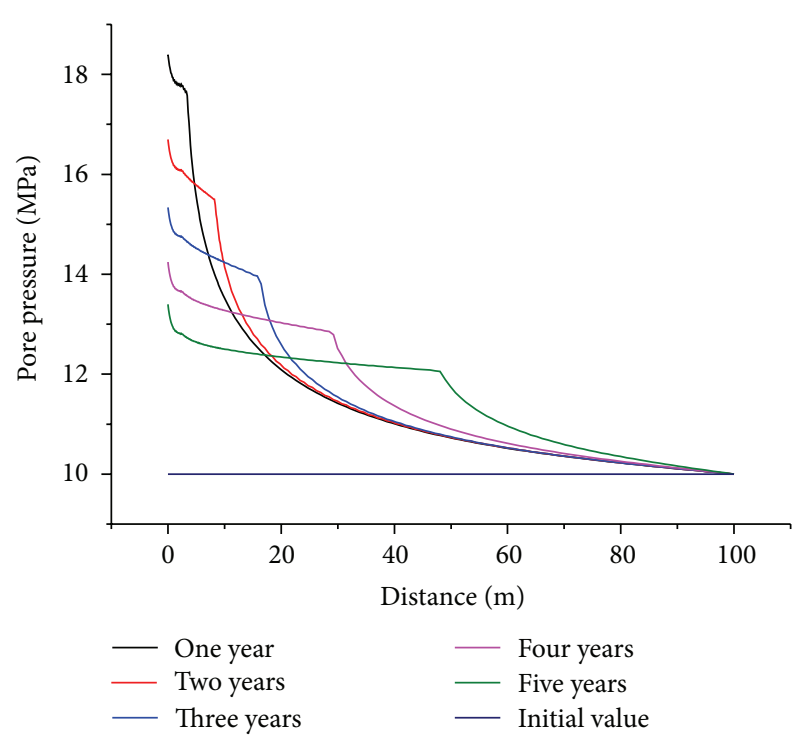

FIgURE 4: Pore pressure evolution along EH line.

where $\overline{\boldsymbol{\sigma}}, p_{w}$, and $\mathbf{I}$ are the effective stress matrix, the pore pressure, and the identity matrix, respectively.

Continuity equation of seepage flow considering large deformation of porous formation is [9]

$$
\frac{\partial}{\partial t}\left(\rho_{w} n_{w}\right)+\nabla \cdot\left(\rho_{w} n_{w} \mathbf{v}_{w}\right)=0
$$

where $\rho_{w}, n_{w}$, and $\mathbf{v}_{w}$ are the porous fluid density, the rock porosity, and the seepage flow velocity vector, respectively.

The kinetics equation of seepage flow is the Darcy's law in the following form [11]:

$$
\mathbf{v}_{w}=-\frac{1}{n_{w} \mu} \mathbf{k} \cdot\left(\nabla p_{w}-\rho_{w} \mathbf{g}\right)
$$

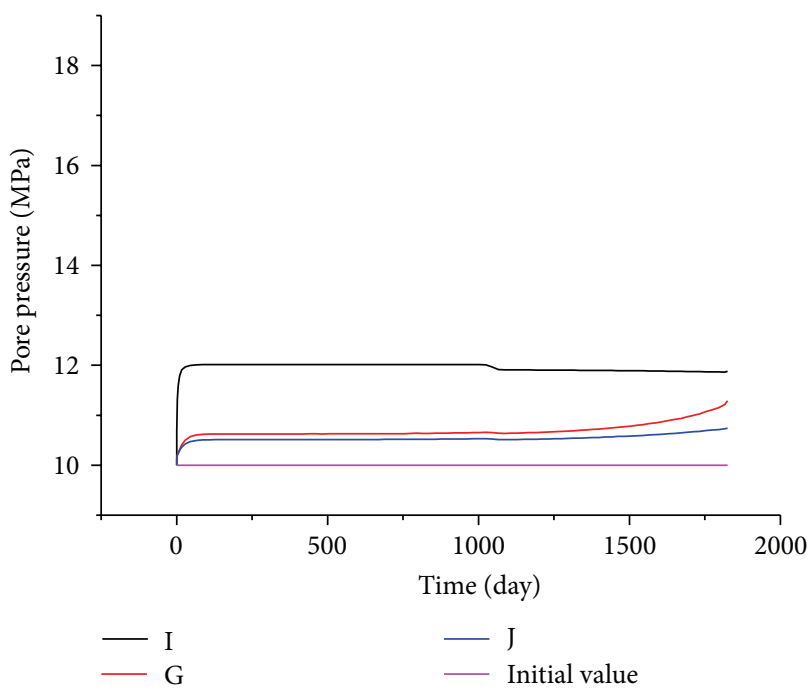

Figure 5: Pore pressure evolutions of points I, J, and G.

where $\mu, \mathbf{k}$, and $\mathbf{g}$ represent the fluid viscosity, the permeability matrix, and the gravity acceleration vector, respectively.

(2) Damage Model and Permeability Change Description. When the deformation of rock material reaches a criterion value, the elastic modulus may degrade gradually as damage progresses. Based on elastic damage mechanics, the damaged elastic modulus $E$ could be related to the original elastic modulus $E_{0}$ with the following formula [12]

$$
E=(1-D) E_{0} .
$$

$D$ in the above formula is the damage factor of the material and it can be written as [5]

$$
D= \begin{cases}0 & \varepsilon \leq \varepsilon_{0} \\ 1-\frac{\varepsilon_{0}}{\varepsilon} & \varepsilon_{0} \leq \varepsilon,\end{cases}
$$

where $\varepsilon$ and $\varepsilon_{0}$ are the minimum principle strain and the threshold strain value of damage initiation.

Experimental results show that rock permeability may change when suffering external loading. Once the rock is damaged, the permeability may jump up steeply. These phenomena can be described as [5]

$$
k= \begin{cases}k_{0} \exp \left(-\beta \bar{\sigma}_{i i}\right) & D=0 \\ \xi k_{0} \exp \left(-\beta \bar{\sigma}_{i i}\right) & D>0,\end{cases}
$$

where $k_{0}$ and $\bar{\sigma}_{i i}$ are the original permeability and the first invariant of effective stress matrix. $\beta$ and $\xi$ are fitting coefficients.

The deformation, strain, stress, and the fluid seepage in the formation during water injection are described by (1)-(7) which couple each other and are highly nonlinear. The 4 node quadrilateral elements are used for describing deformation and seepage in formation. There are 3 nodal unknowns at each node, that is, incremental displacements in 2 directions of cylindrical coordinate system and incremental 


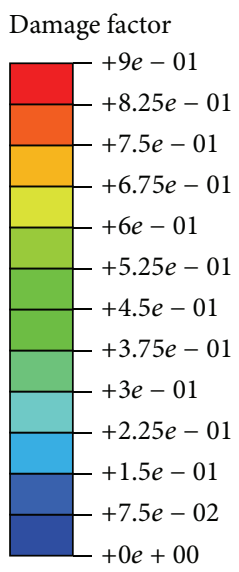

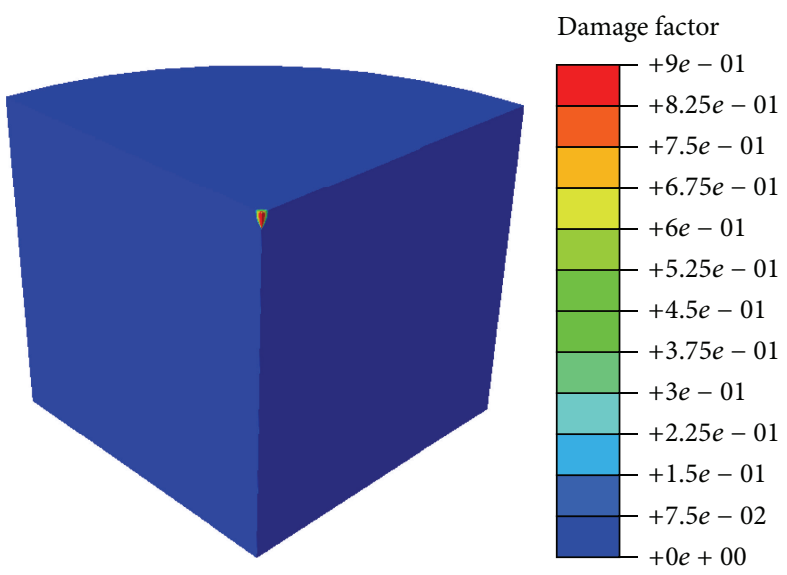

(a) One year

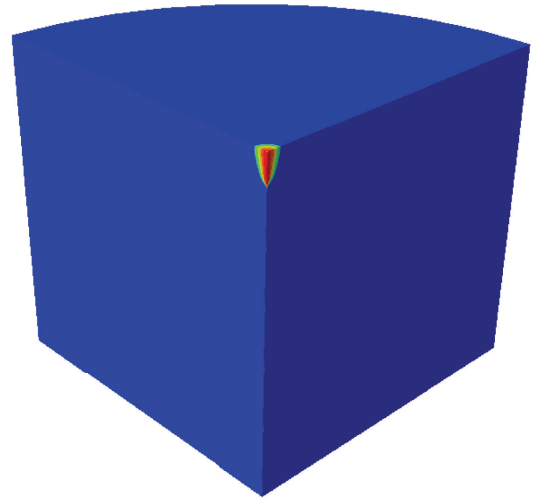

(b) Two years
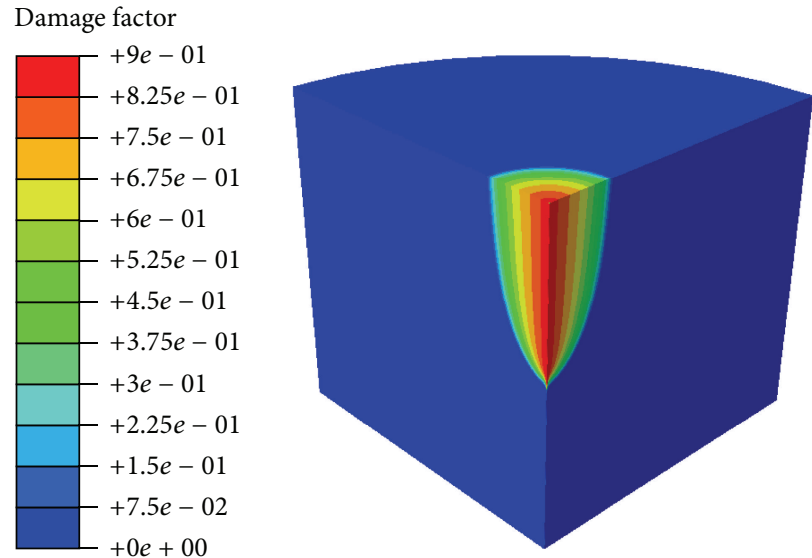

(c) Five years

FIgure 6: Damage factor distributions (The model is rotated by $90^{\circ}$ ).

pore pressure. A corresponding incremental finite element formula was derived in detail [13], and the formula should be solved with the well-known Newton-Raphson iteration scheme. In order to keep the convergence of the simulation, the upper value of damage factor is set as 0.9 .

\section{Computational Model Description}

Most of the wells (including water injection and production wells) are perforated in the pay layer to weaken the casing before normal operation starts. The perforations are helically distributed, and usually its density is rather high (e.g. 816 perforations/meter). Each perforation in a set of helically distributed perforations may develop a damage (or fracture) zone during injecting. The configurations of the damaged zones are very different. The damaged zones connect together, and finally a roughly circular dish-like distributed damaged area forms [14]. Therefore in the paper article we proposed an axial symmetrical fluid-solid coupling finite element model to simulate the long-term water flooding process. Our self-developed user subroutines are incorporated into ABAQUS code to solve (1)-(7) simultaneously. This model can essentially represent the mechanism of the process, but the computation burden is greatly reduced compared to $3 \mathrm{D}$ model.

The rock type of the reservoir is sandstone. The simulation domain is constructed of three layers: one pay layer sandwiched between two barrier layers. The perforation is in the middle of pay layer, and its diameter and length are $8.8 \mathrm{~mm}$ and $0.5 \mathrm{~m}$, respectively. The thickness of pay layer is $5 \mathrm{~m}$. Since the simulation domain is symmetric, the computational model only takes the low half of the whole model as shown in Figure 1.

The radius and height of the computational model are both $100 \mathrm{~m}$. Fluids can flow throughout the whole simulated domain. The diameter of wellbore is $124 \mathrm{~mm}$. Other basic model parameters are initial elastic modulus $=20 \mathrm{GPa}$ (for pay layer) and $25 \mathrm{GPa}$ (for barrier layers), Poisson's ratio $=0.2$ (for pay layer) and 0.25 (for barrier layers), initial permeability $=1 \mathrm{mD}$ (for pay layer) and $0.01 \mathrm{mD}$ (for barrier layers), void ratio $=0.1$ (for pay layer) and 0.01 (for barrier layers), initial pore pressure $=10 \mathrm{MPa}$, the water injection rate $=6.23 \mathrm{~m}^{3} /$ day, water injection duration $=5$ years, threshold strain value of damage initiation $=0.0001$, and fitting coefficient $\xi=20$. 


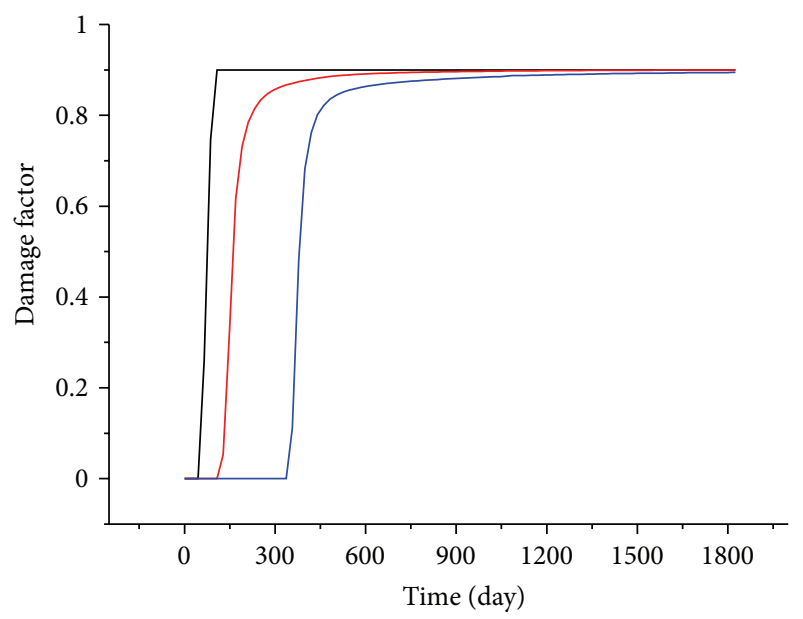

$\mathrm{A}$
$\mathrm{B}$
$\mathrm{F}$

Figure 7: Damage factor evolutions of points A, B, and F.

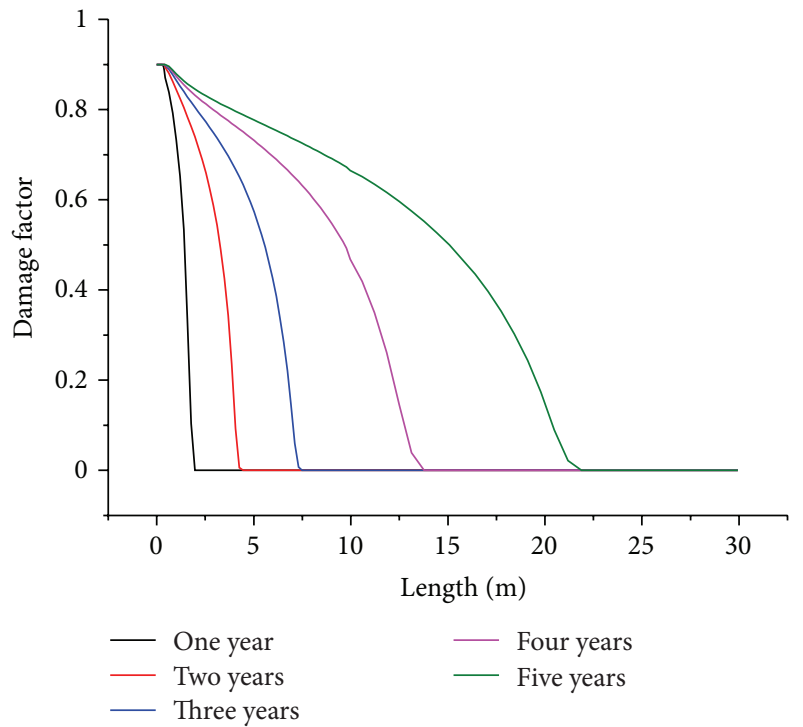

FIGURE 8: Damage factor evolution along AC line.

Ten points A, B, C, D, E, F, G, H, I, and J are designated for the following discussion. A is located at the left bound of the model, and the distance from A to interface is $1.25 \mathrm{~m}$. B, $\mathrm{C}$, and $\mathrm{D}$ are in the same horizontal line with $\mathrm{A}$. The distances from $B$ and $C$ to $A$ are $0.5 \mathrm{~m}$ and $30 \mathrm{~m}$, respectively. $\mathrm{D}$ is located at the right bound of the model. E, F, G, and H are in the same vertical line with $B$. The distances from $F$ and $G$ to interface are $1 \mathrm{~m}$ and $52 \mathrm{~m}$, respectively. $\mathrm{E}$ and $\mathrm{H}$ are located at the top and bottom bounds of the model, respectively. I, J, and $\mathrm{C}$ are in the same vertical line. I and $\mathrm{F}$ are in the same horizontal line. J and $\mathrm{G}$ are in the same horizontal line.

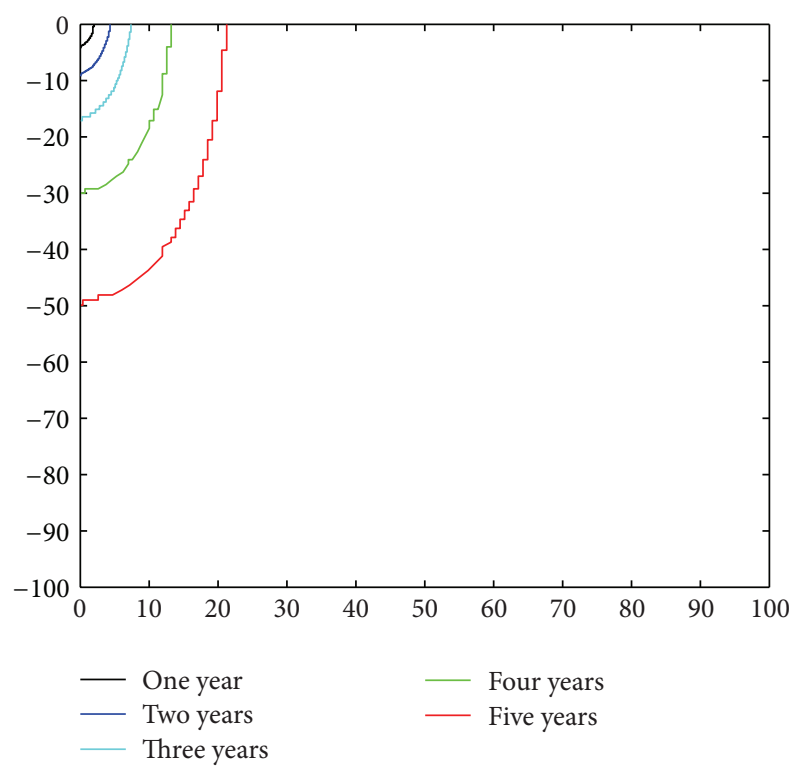

FIGURE 9: Intersections of damaged area and undamaged area at different time.

\section{Results and Discussion}

Figure 2 shows the pressure distributions in the model after different injection years. Figures 3 and 4 depict the pore pressure evolution along $\mathrm{AD}$ line and $\mathrm{EH}$ line, respectively. The following observation can be conducted from the figures. Pore pressure increases (compared to the initial value) due to water injection. The maximum values of pore pressure decrease, and the influenced area enlarges during water injecting. The inflection points in Figures 3 and 4 are the intersection points of damaged and undamaged areas. Figure 5 depicts the pore pressure evolution of points I, J, and G. After 5-year water injection, the maximum pore pressure is $13.8 \mathrm{MPa}$, which is $38 \%$ higher than the initial value. In the area that is $30 \mathrm{~m}$ far away from wellbore (such as points I and $\mathrm{G})$, the pressure is higher than the initial value by over $10 \%$. Higher pressure in reservoir is maintained, and the oil could be swept from the reservoir and pushed towards production wells. This is the main purpose of water flooding.

Figure 6 shows the damage factor distributions after different injection years. Figure 7 depicts the damage factor evolutions of points A, B, and F. Figure 8 depicts the damage factor distribution along $\mathrm{AC}$ line (the horizontal axis represents the distance to point A). Figure 9 depicts the intersection of damaged area and undamaged area. Obviously, the damaged zone is enlarging as water flooding proceeds. Point A is located on the wall of wellbore, where the compression stress is a lot higher, leading to the damage factor that firstly reaches the maximum value. In the region far away from wellbore, the damage factor is comparatively smaller.

Figure 10 presents the first invariant of effective stress distribution after different injection years. It should be pointed out that the values in the figure are the increased parts caused by water injection. With careful observations of the figures 

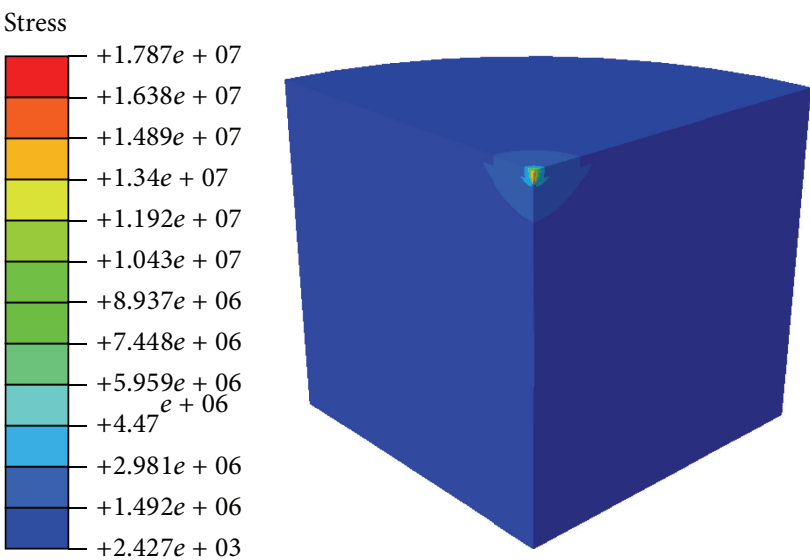

(a) One year

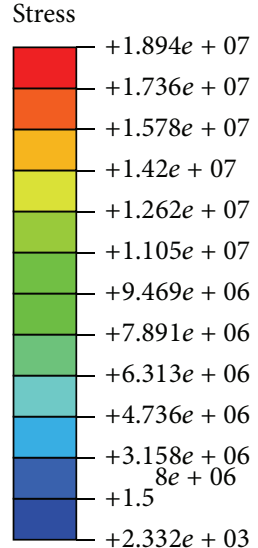

$+2.332 e+03$

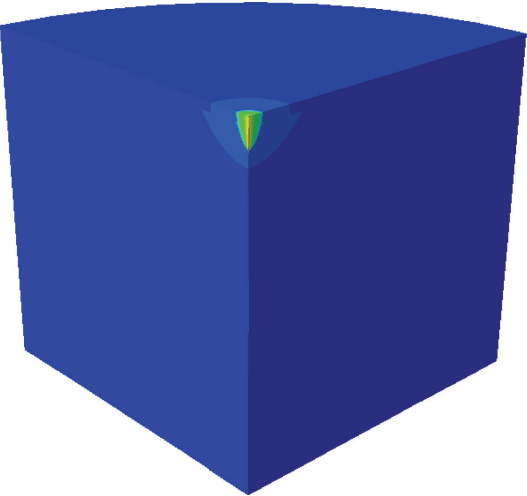

(b) Two years
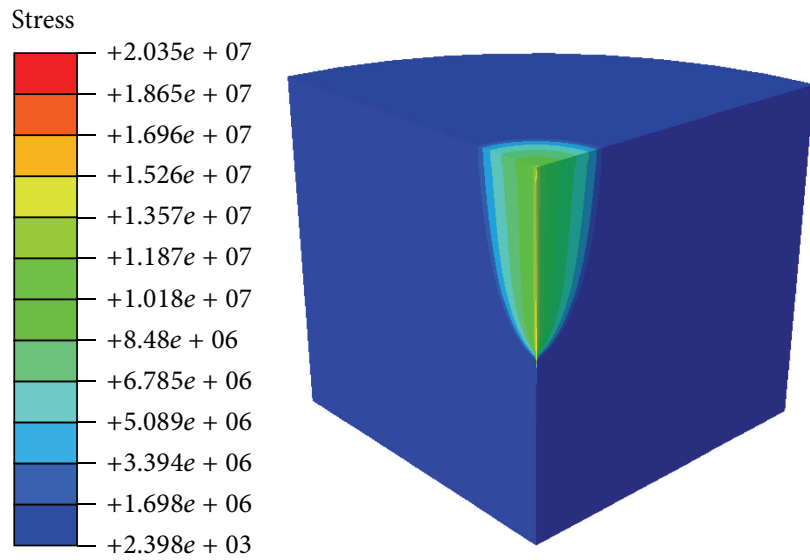

(c) Five years

FIGURE 10: The first invariant of effective stress distribution induced by water injection (The model is rotated by $90^{\circ}$ ).

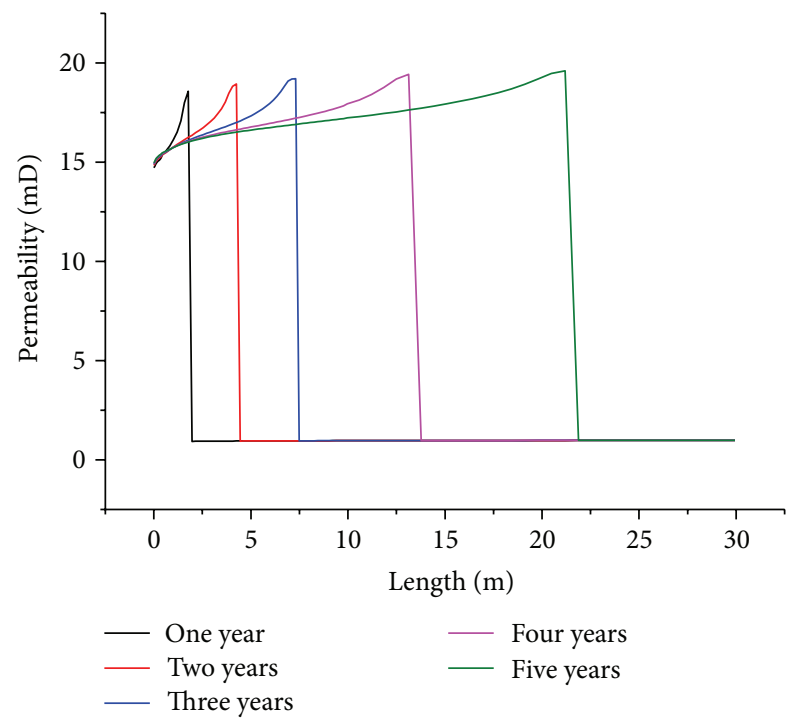

FIGURE 11: The permeability distribution along AC line.

we can find that the maximum values of the first invariant are $17.9 \mathrm{MPa}, 18.9 \mathrm{MPa}$, and $20.4 \mathrm{MPa}$ at the injection point after one, two, and five years of injection, respectively. This high stress concentration results in material damage and may cause casing failure.

Figures 11 and 12 show the permeability along AC and FG lines, respectively. It can be seen that as the distance increases, the permeability firstly increases and then drops. In the zone near wellbore, the stress is higher and accompanying material damage; as a result, the permeability jumps up. But in the undamaged zone, the permeability drops and the value is close to the initial value.

\section{Conclusions}

An axial symmetrical fluid-solid coupling finite element model is established to simulate water flooding process. Our developed user subroutines are incorporated into ABAQUS code to solve the mathematical equations.

Compared to the initial value, water flooding will cause the pore to pressure increase, and the influence area enlarges gradually. After 5-year water injection, the maximum pore pressure may be $38 \%$ higher than the initial value. In the area that is $30 \mathrm{~m}$ far away from wellbore, the pressure is higher than the initial value by over $10 \%$. The purpose of water injection is achieved. 


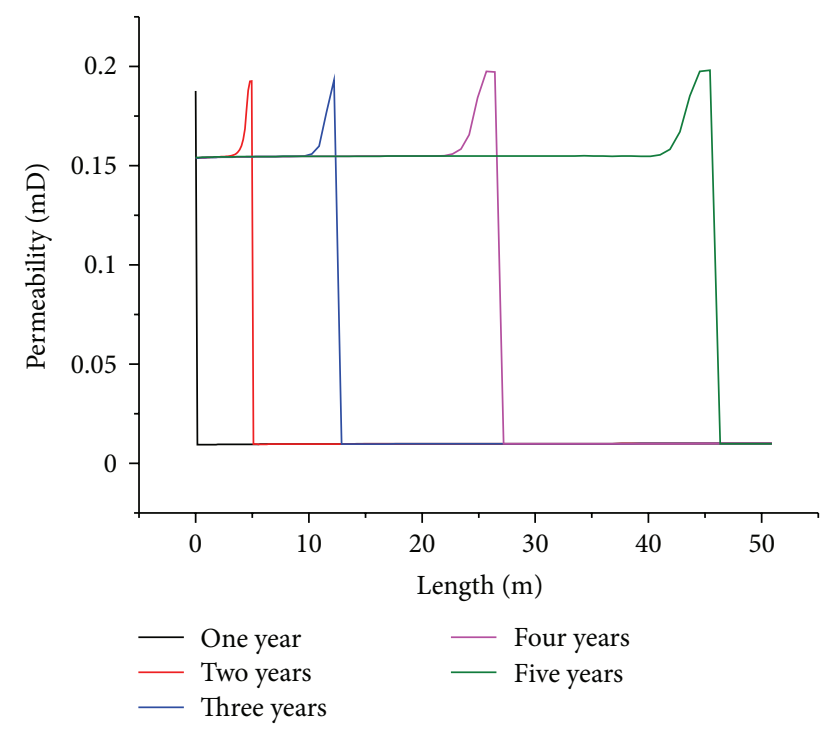

FIgURE 12: The permeability distribution along FG line.

Water injection may cause the formation property change. As water injection proceeds, the compression stress will redistribute and enlarge. As a result the rock material may damage, and the damaged area enlarges during water injecting. In this area, the formation permeability jumps up, leading to the pore pressure decrease. High stress concentration near injection point exists. Attention should be paid on the risk related to casing failure and/or formation fracture in design and performance of water injection.

\section{Nomenclature}

D: Damage factor, dimensionless

E: Damaged elastic modulus of the rock material, $\mathrm{m} / \mathrm{Lt}^{2}$, $\mathrm{Pa}$

$E_{0}$ : Original elastic modulus of the rock material, $\mathrm{m} / \mathrm{Lt}^{2}, \mathrm{~Pa}$

f: Body force vector, $\mathrm{m} / \mathrm{L}^{2} \mathrm{t}^{2}, \mathrm{~Pa} / \mathrm{m}$

g: Gravity acceleration vector, $\mathrm{L} / \mathrm{t}^{2}, \mathrm{~m} / \mathrm{s}^{2}$

I: Identity matrix, dimensionless

k: Permeability matrix, $\mathrm{L}^{2}, \mathrm{~m}^{2}$

$k_{0}$ : Initial permeability, $\mathrm{L}^{2}, \mathrm{~m}^{2}$

$n_{w}$ : Porosity, dimensionless

$p_{w}$ : Porous pressure, $\mathrm{m} / \mathrm{Lt}^{2}$, $\mathrm{pa}$

$\mathbf{v}_{\mathbf{w}}$ : Seepage flow velocity vector, $\mathrm{L} / \mathrm{t}, \mathrm{m} / \mathrm{s}$

$\beta$ : Fitting coefficient, dimensionless

$\varepsilon$ : Minimum principle strain and the threshold value of damage initiation, dimensionless

$\varepsilon_{0}$ : Threshold value of $\varepsilon$, dimensionless

$\mu$ : Fluid viscosity, $\mathrm{m} / \mathrm{Lt}^{3}, \mathrm{~Pa} . \mathrm{s}$

$\rho_{w}$ : Density of porous fluid, $\mathrm{m} / \mathrm{L}^{3}, \mathrm{~kg} / \mathrm{m}^{3}$

$\boldsymbol{\sigma}$ : Total stress matrix, $\mathrm{m} / \mathrm{Lt}^{2}, \mathrm{~Pa}$

$\bar{\sigma}: \quad$ Effective stress matrix, $\mathrm{m} / \mathrm{Lt}^{2}, \mathrm{~Pa}$

$\bar{\sigma}_{i i}$ : First invariant of effective stress tensor, $\mathrm{m} / \mathrm{Lt}^{2}, \mathrm{~Pa}$

$\xi$ : Fitting coefficient, dimensionless.

\section{Acknowledgments}

The authors highly appreciate the financial support of State 863 Projects and PetroChina Innovation Foundation.

\section{References}

[1] M. Latil, Enhanced Oil Recovery, Editions Technip, Paris, France, 1980

[2] B. A. Stenger, A. B. Al-Katheeri, H. H. Hafez, and S. H. AlKendi, "Short-term and long-term aspects of a water injection strategy," in Proceedings of the 13th Abu Dhabi International Petroleum Exhibition and Conference (ADIPEC '08), vol. 116989, pp. 74-86, Abu Dhabi, United Arab Emirates, November 2008.

[3] E. E. Kristian, C. Jerey, I. Orkhan, N. Julian, and A. A. K. Vegard, "Improved oil recovery with water injection," EiT-Gullfaks Village, Norwegian University of Science and Technology in cooperation with Statoil ASA, 2011.

[4] J. A. Wang and H. D. Park, "Fluid permeability of sedimentary rocks in a complete stress-strain process," Engineering Geology, vol. 63, no. 3-4, pp. 291-300, 2002.

[5] C. A. Tang, L. G. Tham, P. K. K. Lee, T. H. Yang, and L. C. $\mathrm{Li}$, "Coupled analysis of flow, stress and damage (FSD) in rock failure," International Journal of Rock Mechanics and Mining Sciences, vol. 39, no. 4, pp. 477-489, 2002.

[6] A. S. Abou-Sayed, K. S. Zaki, G. G. Wang, and M. D. Sarfare, "A mechanistic model for formation damage and fracture propagation during water injection," in Proceedings of the SPE 6th European Formation Damage Conference: Delivering Sustained Production (EFDC '05), vol. 94606, pp. 223-230, Scheveningen, The Netherlands, May 2005.

[7] J. Rutqvist, L. Börgesson, M. Chijimatsu et al., "Modeling of damage, permeability changes and pressure responses during excavation of the TSX tunnel in granitic rock at URL, Canada," Environmental Geology, vol. 57, no. 6, pp. 1263-1274, 2009.

[8] X. R. Ge, J. X. Ren, Y. B. Pu, W. Ma, and H. Sun, Macroscopic and Meso Laboratory Research of Rock and Soil Damage Mechanics, Scientific Press, Beijing, China, 2004.

[9] L. E. Malvern, Introduction to the Mechanics of a Continuous Medium, Prentice-Hall, Upper Saddle River, NJ, USA, 1969.

[10] M. J. Economides and K. G. Nolte, Reservoir Stimulation, John Wiley \& Sons, New York, NY, USA, 3rd edition, 2000.

[11] M. A. Marino and J. N. Luthin, Seepage and Groundwater, Elsevier, New York, NY, USA, 1982.

[12] A. Turon, P. P. Camanho, J. Costa, and C. G. Dávila, "A damage model for the simulation of delamination in advanced composites under variable-mode loading," Mechanics of Materials, vol. 38, no. 11, pp. 1072-1089, 2006.

[13] G. M. Zhang, H. Liu, J. Zhang, H. A. Wu, and X. X. Wang, "Mathematical model and nonlinear finite element equation for reservoir fluid-solid coupling," Rock and Soil Mechanics, vol. 31, no. 5, pp. 1657-1662, 2010 (Chinese).

[14] F. J. Biao, A study of numerical simulation on hydraulic fracture propagation of horizontal fracture, University of Science and Technology of China, 2010. 

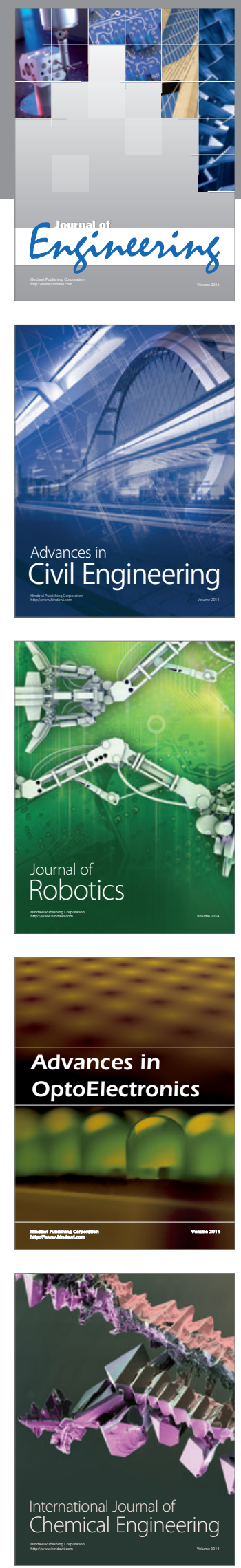

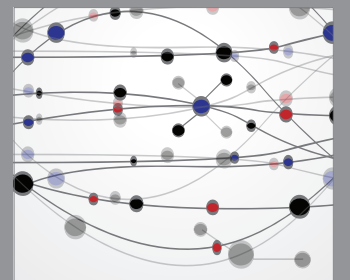

The Scientific World Journal
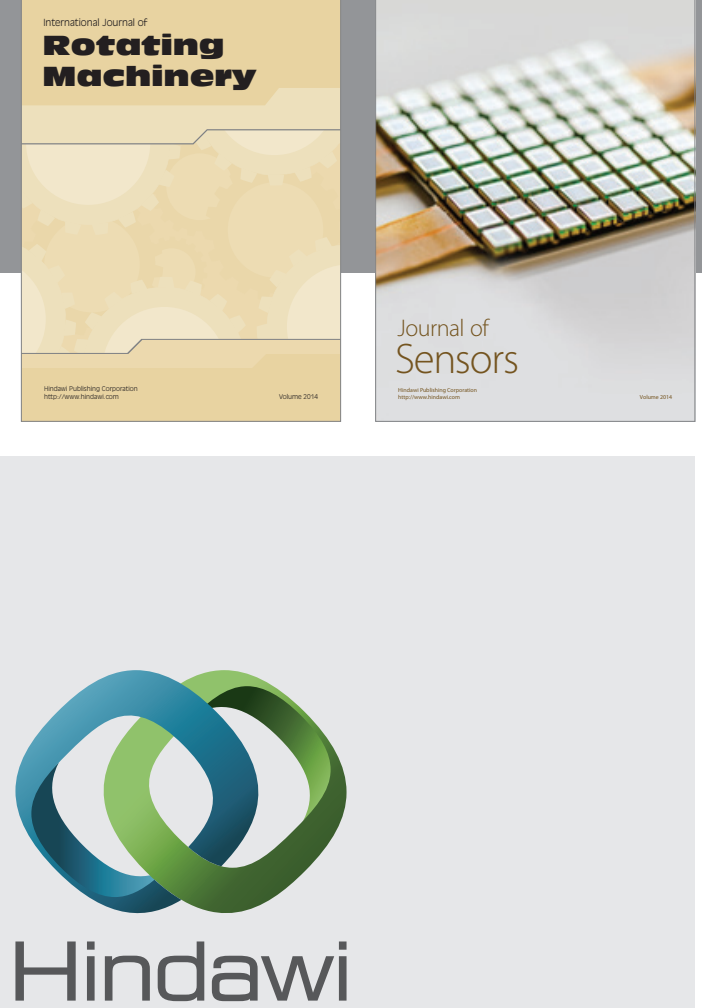

Submit your manuscripts at http://www.hindawi.com
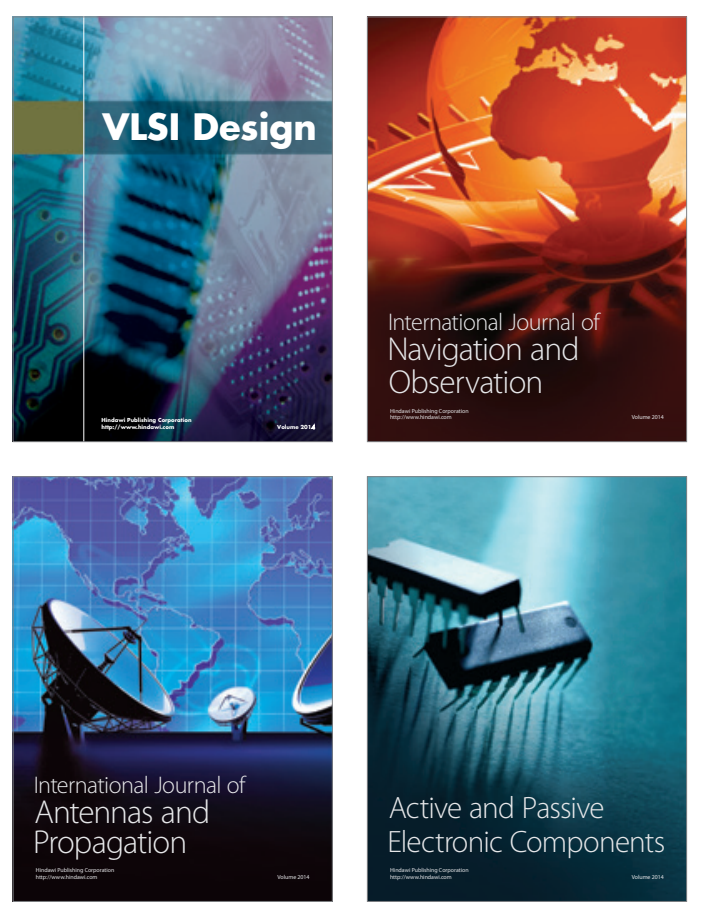
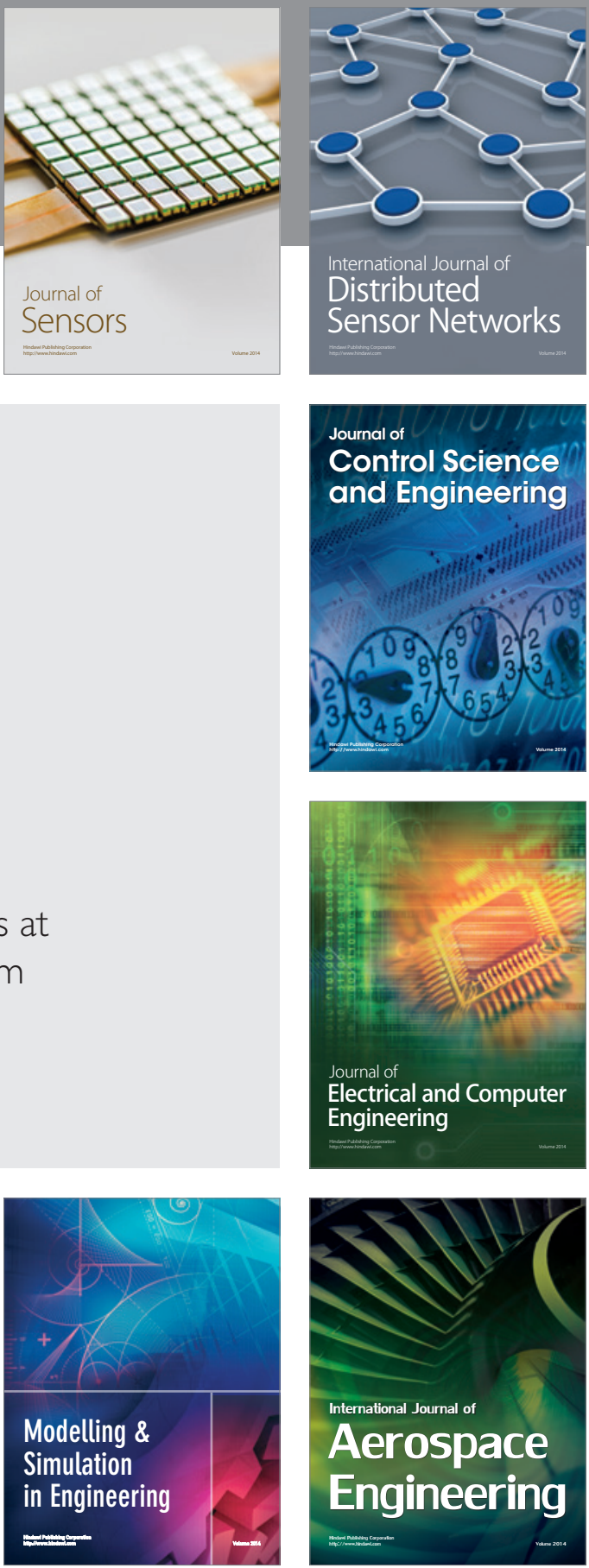

Journal of

Control Science

and Engineering
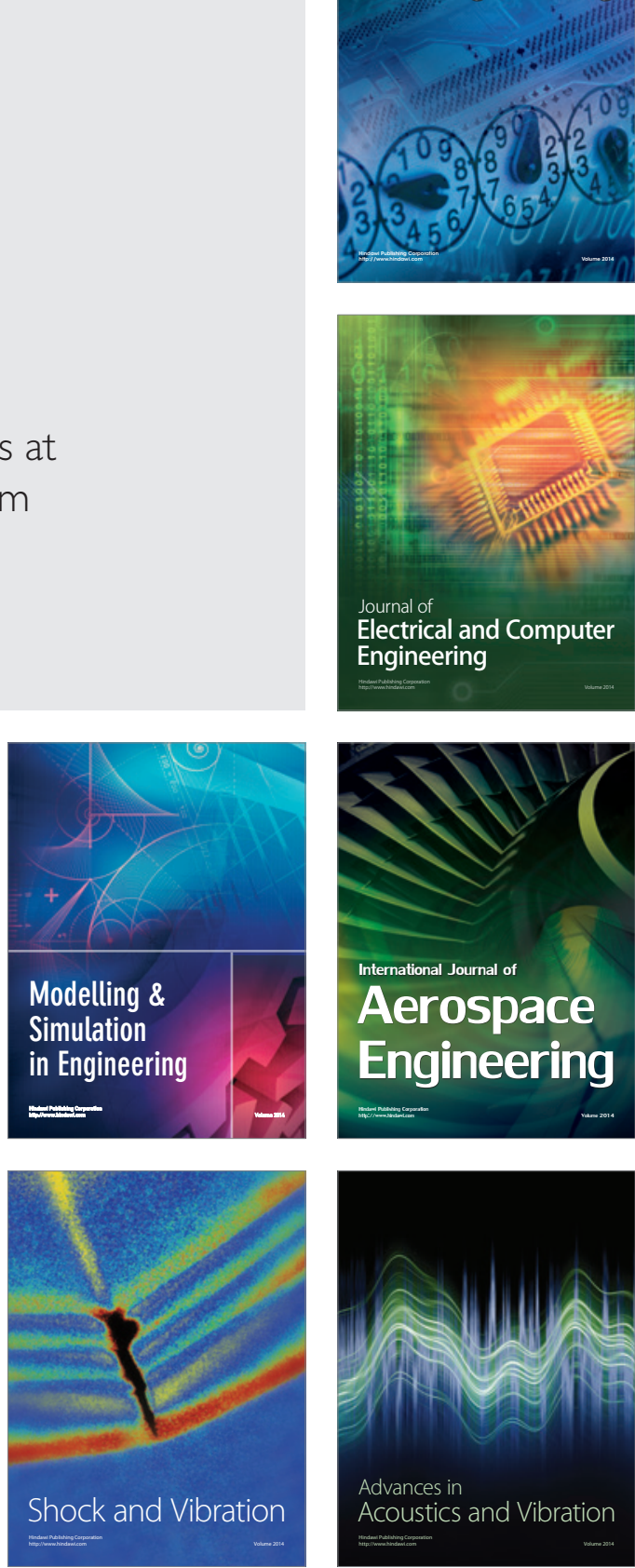